\title{
Segmented linear shape memory polyurethanes with thermoreversible Diels-Alder coupling: Effects of polycaprolactone molecular weight and diisocyanate type
}

\author{
Cs. Lakatos ${ }^{1}$, K. Czifrák ${ }^{1}$, R. Papp ${ }^{1}$, J. Karger-Kocsis ${ }^{2,3}$, M. Zsuga 1 , S. Kéki ${ }^{1 *}$ \\ ${ }^{1}$ Department of Applied Chemistry, University of Debrecen, Egyetem tér 1, H-4032 Debrecen, Hungary \\ ${ }^{2}$ Department of Polymer Engineering, Budapest University of Technology and Economics, Mủegyetem rkp. 3, H-1111 \\ Budapest, Hungary \\ ${ }^{3}$ MTA-BME Research Group for Composite Science and Technology, Müegyetem rkp. 3, H-1111 Budapest, Hungary
}

Received 7 September 2015; accepted in revised form 29 October 2015

\begin{abstract}
Segmented linear polyurethanes (PUs) containing Diels-Alder (DA) adduct were synthesized in toluene solution from poly( $\varepsilon$-caprolactone) (PCL, $M_{\mathrm{n}}=10,25$ and $50 \mathrm{~kg} / \mathrm{mol}$ ), diisocyanate (methylene diphenyl diisocyanate (MDI), 2,4toluene diisocyanate (TDI), 1,6-hexamethylenediisocyanate, (HDI)), furfurylamine (FA) and bismaleimide (BMI). The order of the segments in the PUs was -PCL-MDI-FA-BMI-. The PUs were characterized by size-exclusion chromatography (SEC), different spectroscopic $\left({ }^{1} \mathrm{H}-\mathrm{NMR}\right.$, attenuated total reflectance Fourier-transform infrared, AT-FTIR), thermal and mechanical analysis (differential scanning calorimetry, DSC, dynamical mechanical analysis, DMA). The DA and retro-DA reactions were identified by ${ }^{1} \mathrm{H}-\mathrm{NMR}$ for both the synthesized PU and the coupling components (i.e. FA and BMI). Tensile mechanical and shape memory (SM) properties of the PUs were also determined. The DA coupling in the PU was improved by heat treatment above the melting temperature $\left(T_{\mathrm{m}}\right)$ of PCL. DMA traces showed a plateau-like region above $T_{\mathrm{m}}$ of PCL confirming the presence of a physical network the netpoints of which are given by the hard segments including the DA couplers. This feature suggested good SM behavior that was confirmed both qualitatively and quantitatively.
\end{abstract}

Keywords: smart polymers, polyurethanes, Diels-Alder adduct, mechanical properties, thermal properties

\section{Introduction}

Nowadays, thermoplastic or linear polyurethanes (PUs) are produced in large quantities for different applications, such as linear elastomers and foams [1, 2]. Their market penetration is due to their physicomechanical properties, which can be tailored upon request via their chemical synthesis. Due to their outstanding properties, PUs are widely used in automotive (instrument panel, belt, seals), electric/electronic (cable jacketing, mobile phones), transportation (conveyor belt, tyres), footwear (shoe and shoe sole), medical (catheters) fields, sporting goods, leisure articles (grips) etc. [3-8]. Linear PUs are tra- ditionally produced by reacting diisocyanates (hard segments), long-chain diols of polyesters and/or polyethers (soft segments) and with short-chain diols (socalled chain extenders). These covalently bonded segmented chains undergo phase separation upon cooling from the melt [9]. The resulting morphology is characteristic for traditional thermoplastic elastomers which are 'physically crosslinked'. Moreover, this structure meets the requirements of shape memory polymers (SMPs). SMPs contain 'net points' accounting for shape fixing and reversible 'switches' via which the temporary shaping occurs [10]. In segmented PUs the hard domains form the net points,

\footnotetext{
${ }^{*}$ Corresponding author, e-mail: keki.sandor@science.unideb.hu (C) BME-PT
} 
whereas the soft segment may overtake the switch function. The reversible switch is linked either with the glass transition $\left(T_{\mathrm{g}}\right)$ or with the melting temperature $\left(T_{\mathrm{m}}\right)$ depending whether the long-chain soft segments are amorphous or semicrystalline [11]. The SM behavior of segmented PUs was early recognized thereby credit should be given to Tobushi et al. [12].

Nowadays, already a large body of works addressed the preparation and characterization of shape memory PUs (SMPUs) [13-16]. Research strategies focus now on the creation of multifunctional polymers [17, 18]. As far as SM concerns, attempts are in progress to combine it with self-healing [19]. For self-healing different concepts have been introduced and followed [20]. One of them exploits thermoreversible Diels-Alder (DA) reactions [21, 22]. Due to the thermal reversibility and mild reaction conditions of the Diels-Alder (DA) reaction widely used in the polymer syntheses. The other advantages of this reaction are as follows: both DA and retro-DA (rDA) reaction undergo without catalyst and no byproducts forms. The DA adducts form by the reaction of a conjugated diene and a dienophile at a temperature range from 20 to $90^{\circ} \mathrm{C}$ and can be cleaved via rDA reaction above $120^{\circ} \mathrm{C}$ [23-27]. The retro reaction, i.e. break-up of the DA adduct, has a very promising additional benefit for linear PUs, namely reduction of the melt viscosity. Low melt viscosity is essential for molded parts having fine surface pattern, long flow routes, or the like. In addition, through DA adducts the degradation behavior of PUs may also be tuned. Therefore, it is of great interest to study the effect of DA adducts in the segmented chain of PUs on their mechanical and shape memory behavior.

This work is aimed at synthesizing various segmented linear PUs containing DA couplings in the main chains and studying their basic mechanical, shape memory and thermomechanical behaviors. Based on our former works [28] poly(E-caprolactone) (PCL) with different high molecular weights proved to act as an excellent 'switch' in SMPUs [29]. Therefore, for the syntheses of shape memory PUs PCLs with high molecular weights served as diols. As diisocyanates aliphatic and aromatic types have been selected. DA adducts in the main chain were produced by furan-maleimide reaction [23].

\section{Experimental section}

\subsection{Materials}

For synthesis of the obtained PUs the following materials were used. As diols PCL $\left(M_{\mathrm{n}}=10 \mathrm{~kg} / \mathrm{mol}\right.$, Sigma-Aldrich Chemical Co (Chemie GmbH, Germany); $\mathrm{CAPA}^{\circledR} 6250, M_{\mathrm{n}}=25 \mathrm{~kg} / \mathrm{mol} ; \mathrm{CAPA}^{\circledR}$ $6500, M_{\mathrm{n}}=50 \mathrm{~kg} / \mathrm{mol}$, Perstorp Holding AB, Malmö, Sweden) were selected. For the hard segment formation 4,4'-methylene diphenyl diisocyanate (MDI), 2,4-toluene diisocyanate (TDI), 1,6-hexamethylene diisocyanate (HDI) (reagent grades, Sigma-Aldrich Chemical Co (Chemie GmbH, Germany)) served. Furfurylamine (FA) and 1,1'-(methylene di-4,1phenylene)bismaleimide (BMI) (reagent grade) was purchased from Sigma-Aldrich Chemical Co (Chemie $\mathrm{GmbH}$, Germany). Toluene (analytical grade of LabScan Analytical Sciences, Gliwice, Poland) was distilled over $\mathrm{P}_{2} \mathrm{O}_{5}$ and stored on sodium wire until use.

\subsection{Synthesis of PUs}

The PUs differed in the $M_{\mathrm{n}}$ of PCL, type of the diisocyanates and ratio of the components used for their synthesis. PU 1 was produced as described below. Typical procedure for the synthesis of PU 1: $5.0 \mathrm{~g}$ PCL $\left(5 \cdot 10^{-4} \mathrm{~mol}, M_{\mathrm{n}}=10 \mathrm{~kg} / \mathrm{mol}\right)$ was dissolved in hot toluene $60-80^{\circ} \mathrm{C}(50 \mathrm{~mL})$ under a nitrogen atmosphere in a $250 \mathrm{~mL}$ four-neck flask (equipped with mechanical stirrer, dropping funnel, condenser and nitrogen inlet). Tin(II) ethylhexanoate (reagent grade, Sigma-Aldrich) in $2 \mathrm{~mol} \%$ amount was used as catalyst. To prepare the prepolymer with isocyanate end groups $0.375 \mathrm{~g}$ MDI $\left(1.5 \cdot 10^{-3} \mathrm{~mol} / 5 \mathrm{~mL}\right.$ toluene, 3 equiv.) was added to the mixture and reacted for 2-3 hour [h] at $100-110^{\circ} \mathrm{C}$. To form the DA adduct, $0.05 \mathrm{~g}(49 \mu \mathrm{L}) \mathrm{FA}\left(1 \cdot 10^{-3} \mathrm{~mol}, 2\right.$ equiv. $)$ was added to the isocyanate ended pre-polymer in one portion at $20^{\circ} \mathrm{C}$ and heated to $80^{\circ} \mathrm{C}$ and kept there for $0.5 \mathrm{~h}$. It was followed by the addition of $0.18 \mathrm{~g} \mathrm{BMI}$ $\left(5 \cdot 10^{-4}\right.$ mol, 1 equiv. $)$ at the same temperature and heated at $100-110^{\circ} \mathrm{C}$ for $1 \mathrm{~h}$. Accordingly, the composition of this PU 1 is PCL(10)-MDI-FA-BMI/ $1: 3: 2: 1$, where (10) refers to the $M_{\mathrm{n}}$ of PCL in $\mathrm{kg} / \mathrm{mol}$ unit.

PU 2-PU 10 were synthesized according to the procedure described above except that the amounts of BMI were doubled. The PUs were prepared using the 


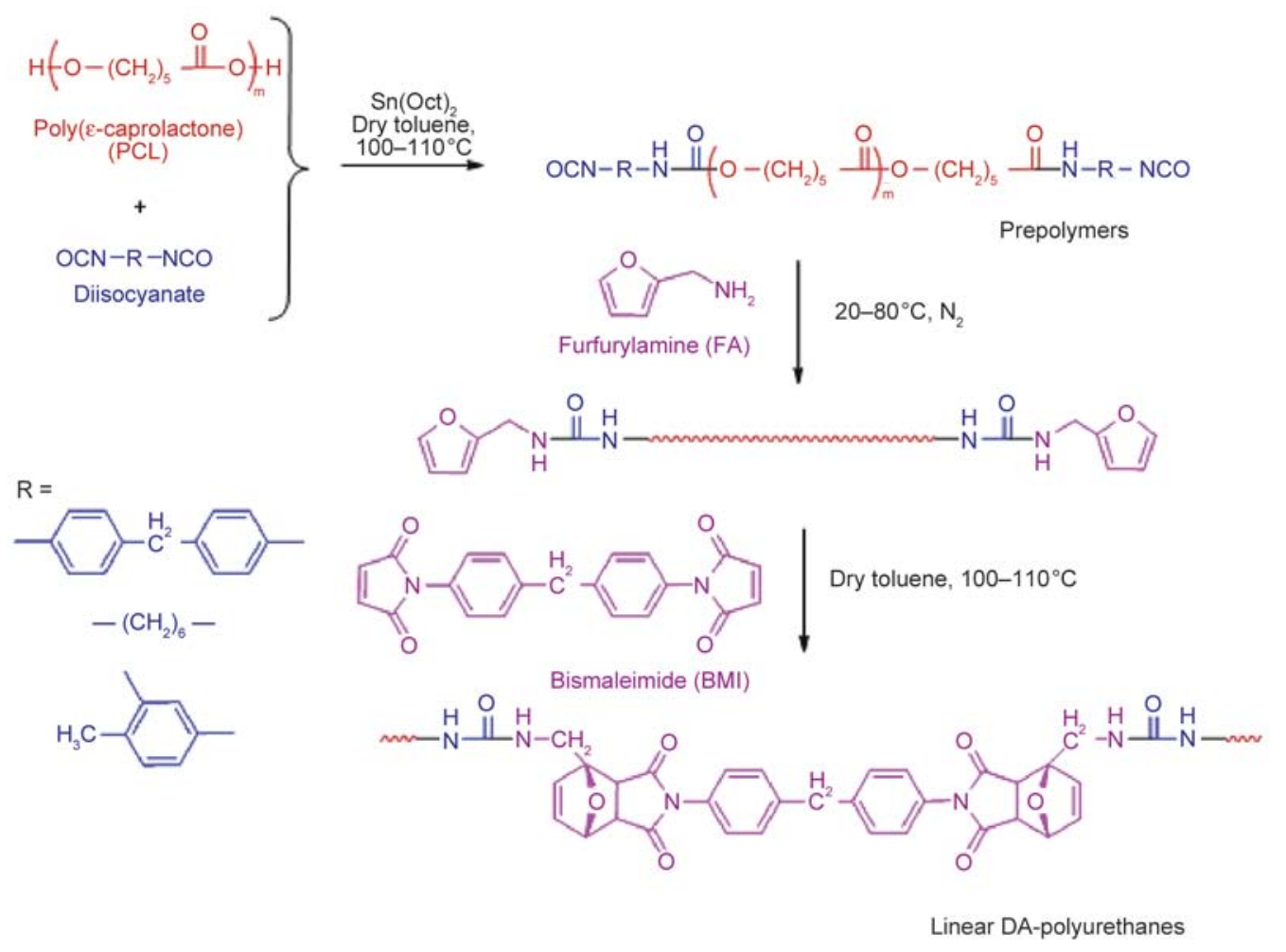

Figure 1. Synthetic pathway for the preparation of DA-adduct containing linear polyurethanes

following compositions: PCL (different $M_{\mathrm{n}}$ )-diisocyanate (MDI, TDI, HDI)-FA-BMI/1:3:2:2. The synthetic pathway of the PUs is summarized in Figure 1 .

It is the right place to mention that the above composition ratios were selected according to our experience. During the related works it turned out that the $\mathrm{OH} / \mathrm{NCO}$ ratio for the prepolymer formation should be preferentially $1: 3$ [28], corresponding to the above molar ratio, viz. 1:3. During the syntheses the $M_{\mathrm{n}}$ of PCL and the type of the diisocyanate were systematically changed to examine their effects on the properties of the resulting PUs.

Diels-Alder adducts were obtained through the reaction between furan and maleimide groups. The former was obtained by reacting the isocyanate functionalized prepolymer with FA. Coupling of FA endfunctionalized polymers with BMI resulted in the formation of DA adducts. Note that no additional chain extending diol was involved in the synthesis. For the syntheses of PU 2 to PU 10 the molar ratio of BMI was raised from 1 to 2, which yielded improved mechanical properties. Yield of the synthesis of the PUs varied between 85 and $98 \%$ for this PU series.

The solutions containing the final linear PUs were poured onto Teflon ${ }^{\circledR}$ plates and dried in air resulting in yellow elastic films. Their coding, composition, $M_{\mathrm{n}}$ and Shore A hardness data are listed in Table 1.

\subsection{Characterization}

Size-exclusion chromatography (SEC) was used to determine the number- and weight-average molecular weight $\left(M_{\mathrm{n}}\right.$ and $M_{\mathrm{w}}$, respectively) and thus the polydispersity $\left(M_{\mathrm{w}} / M_{\mathrm{n}}\right)$ of the linear PUs prepared. SEC chromatograms were recorded in tetrahydrofuran (THF) at a flow rate of $0.5 \mathrm{~mL} / \mathrm{min}$ with a Waters chromatograph equipped with four gel columns $(4.6 \times 300 \mathrm{~mm}, 5 \mu \mathrm{m}$ Styragel columns: HR 0.5, 1, 2 and 4), Waters Alliance e2695 HPLC pump, and with a Waters 2414 refractive index detector, Waters Corp., Milford, MA, USA). SEC was calibrated with polystyrene standards.

${ }^{1} \mathrm{H}-\mathrm{NMR}$ spectra were recorded with a Bruker AM $360\left(360 / 90 \mathrm{MHz}\right.$ for ${ }^{1} \mathrm{H} /{ }^{13} \mathrm{C}$ ) spectrometer (Bruker, Karlsruhe, Germany). Deuterated chloroform was used as solvent. Chemical shifts were referenced to the ${ }^{1} \mathrm{H}$ signal of $\mathrm{Me}_{4} \mathrm{Si}$, that was used as standard. FA and BMI were reacted separately at different temperatures in toluene and their ${ }^{1} \mathrm{H}-\mathrm{NMR}$ spectra recorded and analyzed in order to support the proper assignments of the ${ }^{1} \mathrm{H}$ signals of DA adducts in the ${ }^{1} \mathrm{H}-\mathrm{NMR}$ spectra of the PUs.

Attenuated total reflectance (ATR) Fourier-transform infrared (AT-FTIR) spectra were recorded on a Perkin Elmer Instruments Spectrum One FTIR spectrometer equipped with a Universal ATR Sampling Accessory (PerkinElmer Inc. Waltham, MA, USA). 
The polymer was irradiated by IR beam through a special diamond-zinc-selenium composite prism. The average film thickness of the specimens was ca. $0.5 \mathrm{~mm}$. Four scans were taken for each sample. The spectra were evaluated by Spectrum ES 5.0 program.

Heat treatment of polymers was carried out by hot pressing using 20 bar pressure at $90^{\circ} \mathrm{C}$ for $45 \mathrm{~min}$. This treatment was expected to improve the DA coupling in the main chain.

Shore A hardness was measured according to the EN ISO 868 standard with a Zorn type instrument.

Tensile tests were carried out according to the EN ISO 527-1 standard. Computer-controlled Instron 4302 type tensile testing machine (Instron, Darmstadt, Germany), equipped with a $1 \mathrm{kN}$ load cell, was used. At least three dumbbell specimens were cut (clamped length $60 \mathrm{~mm}$ ) and tensile loaded at a crosshead speed of $50 \mathrm{~mm} / \mathrm{min}$. The thickness of the specimens varied between $0.3-1.1 \mathrm{~mm}$.

The thermal properties of the synthesized PUs were examined by Differential Scanning Calorimetry (DSC). DSC tests were carried out in a DSC Q2000 (TA Instruments, Newcastle, DE, USA) equipment operating at $10^{\circ} \mathrm{C} / \mathrm{min}$ heating rate. Nitrogen flushing was used as protective atmosphere. The weight percentage of the crystalline PCL $\left(C_{\mathrm{r}}\right)$ was calculated by Equation (1) [30]:

$$
C_{\mathrm{r}}=\frac{\Delta H_{\mathrm{m}}}{\chi_{\mathrm{A}} \cdot \Delta H_{\mathrm{m}}^{\circ}} \cdot 100
$$

where $\Delta H_{\mathrm{m}}$ is the heat of fusion of the investigated PU, $\chi_{\mathrm{A}}$ is the weight fraction of PCL in the corresponding PU, $\Delta H_{\mathrm{m}}^{\circ}$ is the heat of fusion of the pure $100 \%$ crystalline PCL. For the latter $135.31 \mathrm{~J} / \mathrm{g}$ has been taken [31].

Dynamic mechanical analysis (DMA) testing of the PUs was carried out in DMA Q800 device of TA Instruments (Newcastle, DE, USA). DMA traces were monitored in tension mode (dimension of the specimens: length: $25 \mathrm{~mm}$, clamped length: $12 \mathrm{~mm}$, width: $7 \mathrm{~mm}$, thickness: ca. $0.5 \mathrm{~mm}$ ) at an oscillation amplitude of $0.2 \%$ setting a frequency of $1 \mathrm{~Hz}$ and a static load of $1 \mathrm{~N}$. The temperature was varied between -10 and $130^{\circ} \mathrm{C}$ with a heating rate of $3{ }^{\circ} \mathrm{C} / \mathrm{min}$.

Shape memory properties were evaluated in tensile mode using the above DMA device. The specimens (clamped length $\times$ width $\times$ thickness $=$ ca. $12 \times 7 \times$ $0.5 \mathrm{~mm}$ ) were stretched after $10 \mathrm{~min}$ holding at $80^{\circ} \mathrm{C}$ at a strain rate of $40 \% / \mathrm{min}$, followed by cooling quickly the specimen to $20^{\circ} \mathrm{C}$. The stress was then released and the shape fixity $\left(R_{\mathrm{f}}\right)$ determined. Shape recovery $\left(R_{\mathrm{r}}\right)$ was measured at $0.1 \mathrm{~N}$ loading of the specimens (quasi free recovery) by reheating the specimens at $1{ }^{\circ} \mathrm{C} / \mathrm{min}$ heating rate from 20 to $80^{\circ} \mathrm{C}$ and holding there for $10 \mathrm{~min}$. The shape fixity $\left(R_{\mathrm{f}}\right)$ and shape recovery ratios $\left(R_{\mathrm{r}}\right)$ are defined as by Equations (2) and (3):

$$
\begin{aligned}
& R_{\mathrm{f}}[\%]=\frac{l_{\mathrm{d}}-l_{0}}{l_{80 \%}-l_{0}} \cdot 100 \\
& R_{\mathrm{r}}[\%]=\frac{l_{\mathrm{d}}-l_{\mathrm{f}}}{l_{\mathrm{d}}-l_{0}} \cdot 100
\end{aligned}
$$

where $l_{\mathrm{d}}$ - the sample length after removal of the tensile load during shape fixing at $20^{\circ} \mathrm{C}, l_{0}$ - the clamped length of the sample at $20^{\circ} \mathrm{C}, l_{80 \%}$ - the length after tensile stretching for $80 \%$, and $l_{\mathrm{f}}-$ the final recovered length of the stretched specimen.

\section{Results and discussion}

\subsection{Molecular characteristics of the linear PUs}

According to Figure 1, linear segmented PUs, composed of soft segment PCL with varying $M_{\mathrm{n}}$, hard segment diisocyanate (MDI, HDI, TDI) and the DA coupling (by reacting the furan of FA and BMI), were produced. The compositions of PUs synthesized PU 1 to PU 10 are listed in Table 1. All PUs were highly ductile materials with rather high Shore A hardness.

The SEC traces of the starting PCLs and the synthesized linear PUs 1-10 are shown in Figure 2. The SEC traces of the synthesized PUs appeared at lower retention volumes (i.e., at higher $M_{\mathrm{n}}$ ) than those of the starting PCLs, supporting a successful coupling.

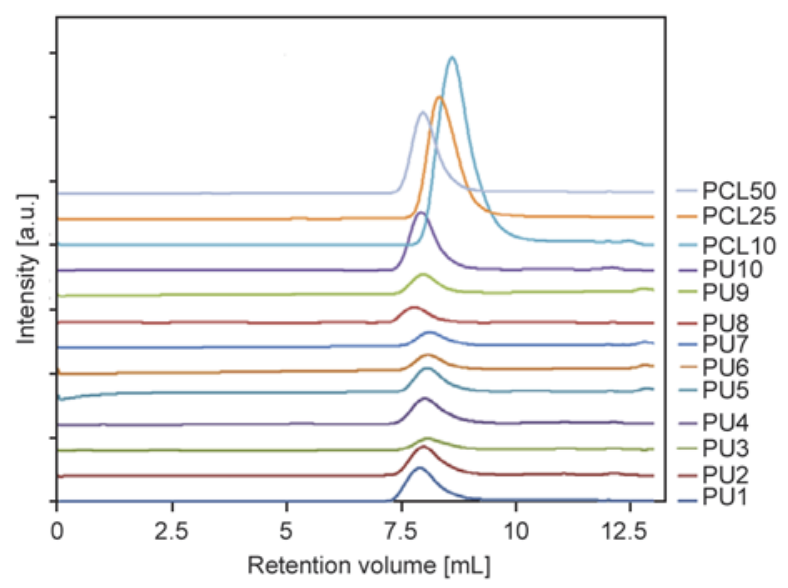

Figure 2. SEC traces of starting PCLs and the synthesized PUs $1-10$ 
Table 1. Composition and basic molecular characteristics of the linear PUs synthesized

\begin{tabular}{|c|l|c|c|c|}
\hline Code & Composition/monomer ratio & $\begin{array}{c}\boldsymbol{M}_{\mathbf{n}} \\
{[\mathbf{k g} / \mathbf{m o l}]}\end{array}$ & $\boldsymbol{M}_{\mathbf{w}} / \boldsymbol{M}_{\mathbf{n}}$ & Shore A hardness \\
\hline & PCL(10) & 10.4 & 1.60 & - \\
\hline & PCL(25) & 23.2 & 1.80 & - \\
\hline & PCL(50) & 51.9 & 1.80 & - \\
\hline PU 1 & PCL(10)-MDI-FA-BMI/1:3:2:1 & 76.0 & 1.95 & 94 \\
\hline PU 2 & PCL(10)-MDI-FA-BMI/1:3:2:2 & 66.4 & 1.90 & 95 \\
\hline PU 3 & PCL(10)-HDI-FA-BMI/1:3:2:2 & 53.6 & 1.90 & 81 \\
\hline PU 4 & PCL(10)-TDI-FA-BMI/1:3:2:2 & 67.3 & 2.00 & 84 \\
\hline PU 5 & PCL(25)-MDI-FA-BMI/1:3:2:2 & 67.2 & 1.60 & 96 \\
\hline PU 6 & PCL(25)-HDI-FA-BMI/1:3:2:2 & 61.6 & 1.60 & 94 \\
\hline PU 7 & PCL(25)-TDI-FA-BMI/1:3:2:2 & 116.7 & 1.60 & 90 \\
\hline PU 8 & PCL(50)-MDI-FA-BMI/1:3:2:2 & 95.9 & 1.50 & 92 \\
\hline PU 9 & PCL(50)-HDI-FA-BMI/1:3:2:2 & 85.8 & 1.70 & 90 \\
\hline PU 10 & PCL(50)-TDI-FA-BMI/1:3:2:2 & \\
\hline
\end{tabular}

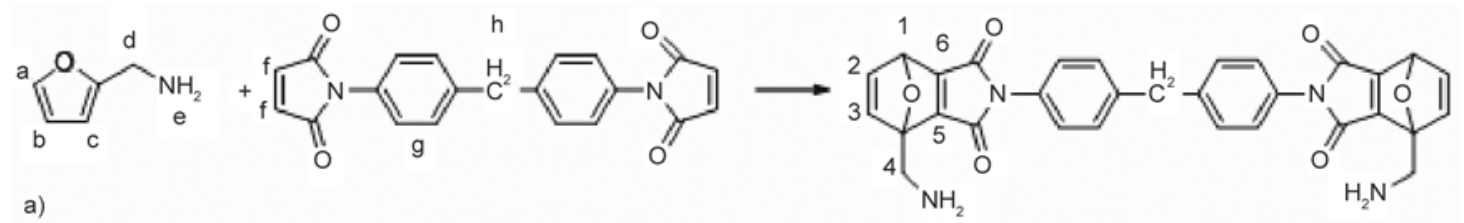

\begin{tabular}{|c|c|c|}
\hline Compound & Protons & $\boldsymbol{\delta}$ [ppm] in $\mathbf{C D C l}_{3}$ \\
\hline & $\mathrm{a}$ & 7.35 \\
FA & $\mathrm{b}$ & 6.31 \\
& $\mathrm{c}$ & 6.12 \\
& $\mathrm{~d}$ & 3.82 \\
& $\mathrm{e}$ & 1.45 \\
\hline \multirow{2}{*}{ BMI } & $\mathrm{f}$ & 6.84 \\
& $\mathrm{~g}$ & $7.31-7.26$ \\
\hline & $\mathrm{h}$ & 4.03 \\
\hline \multirow{3}{*}{ DA adduct } & 1 endo & 5.36 \\
& 1 exo & 4.53 \\
& 2.3 exo, endo & $6.58-6.22$ \\
& 4 endo, exo $+\mathrm{h}$ & $4.01-3.90$ \\
& endo exo & 3.33 \\
& 5 endo & $3.15-3.00$ \\
\hline
\end{tabular}

b)

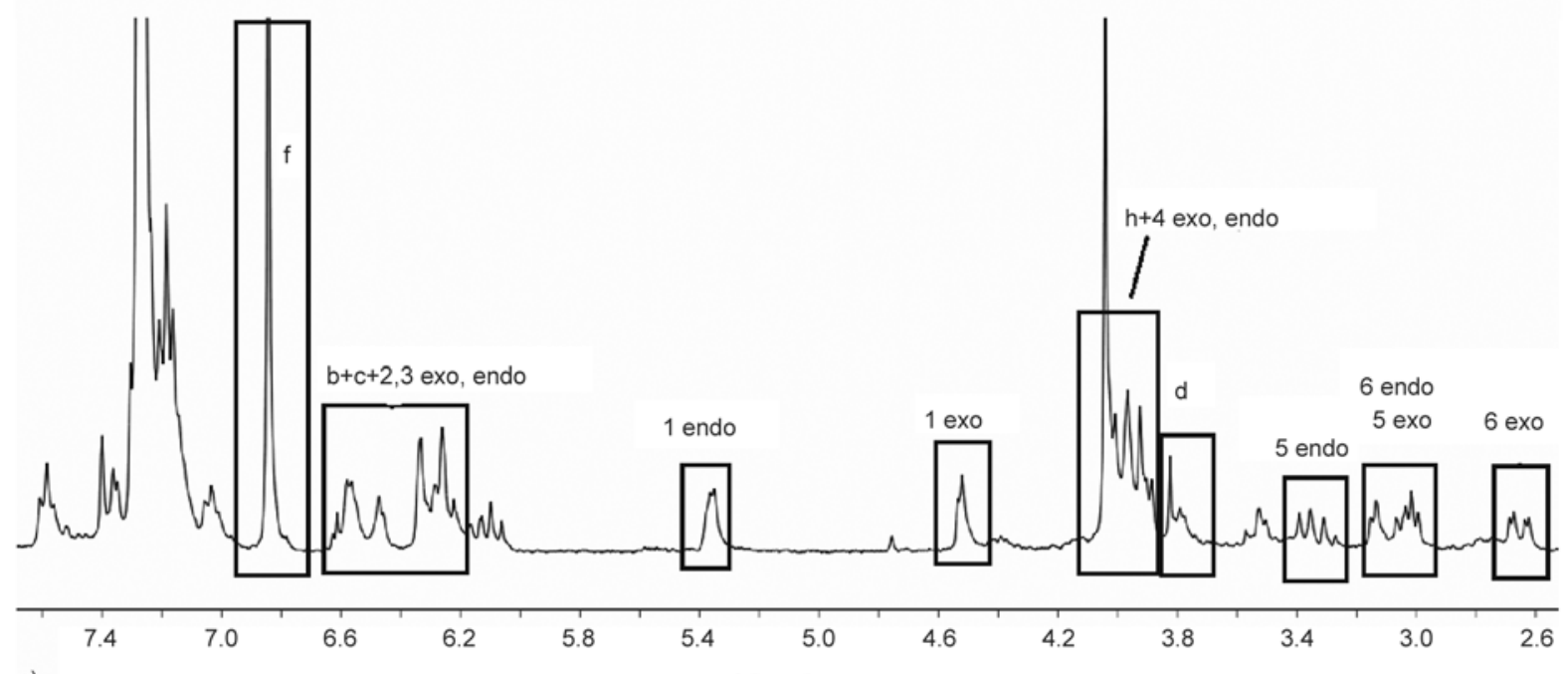

c)

Figure 3. Proton assignments of FA, BMI and the corresponding DA adduct $(a, b)$ and a representative ${ }^{1} \mathrm{H}-\mathrm{NMR}$ spectrum of DA reaction between FA and BMI at $25^{\circ} \mathrm{C}$ (c) 
The $M_{\mathrm{n}}$ and polydispersity $\left(M_{\mathrm{w}} / M_{\mathrm{n}}\right)$ values, obtained from SEC measurements, are compiled in Table 1. $M_{\mathrm{n}}$ values of the DA adduct containing linear PUs with PCL of $M_{\mathrm{n}}=10 \mathrm{~kg} / \mathrm{mol}$ (PUs 1-4) are between 53.6 and $76 \mathrm{~kg} / \mathrm{mol}$. This suggests the formation of PU chains containing 5-7 PCL units. In contrary, PUs 5-7 with PCL of $M_{\mathrm{n}}=25 \mathrm{~kg} / \mathrm{mol}$ includes 2 PCL units based on the measured $M_{\mathrm{n}}$ values (61.6$67.3 \mathrm{~kg} / \mathrm{mol}$ ). Similar amount (i.e. 2 units) of PCL (according to the measured $M_{\mathrm{n}}$ values (85.8-116.7)) may be incorporated in PUs 8-10 containing PCL of $M_{\mathrm{n}}=50 \mathrm{~kg} / \mathrm{mol}$. The polydispersity changed within a narrow range (cf. Table 1).

Comparing PUs 5-7 and PUs 8-10, where the coupling diisocyanates were different the $M_{\mathrm{n}}$ decreased according to the order MDI $>$ HDI $>$ TDI. This tendency is more pronounced for the PUs containing PCL with the highest $M_{\mathrm{n}}$ (PU 8-10) than for the series with $M_{\mathrm{n}}=25 \mathrm{~kg} / \mathrm{mol}$ PCL (PU 5-7). However, incorporation of HDI resulted in the lowest $M_{\mathrm{n}}$ value $(53.6 \mathrm{~kg} / \mathrm{mol})$ for PUs $2-4$. In addition, as general trend it can be established that MDI provided PUs with the highest $M_{\mathrm{n}}$.

To identify the proton signals of the DA adducts in the ${ }^{1} \mathrm{H}-\mathrm{NMR}$ spectra of linear PUs, first the reaction of unprotected FA and BMI was studied as model reaction. FA and BMI were reacted at 25, 60, 100 and $120^{\circ} \mathrm{C}$ for up to $23 \mathrm{~h}$ in dry toluene. Figure 3 illustrates the composition of the reaction mixture after 1 hour at $25^{\circ} \mathrm{C}$. The distinct peaks at $\delta=6.84$, $4.03 \mathrm{ppm}$ are assigned to protons $\mathbf{f}$ and $\mathbf{h}$ of BMI while peak at $3.82 \mathrm{ppm}$ belongs to proton $\mathbf{d}$ of FA. New chemical shifts at $\delta=6.58-6.22,5.36,4.53$, 4.01-3.90, 4.33 and $2.65 \mathrm{ppm}$ can be assigned to the protons $1-6$ of DA adduct. Considering the nature of DA reaction exo- and endo-adducts may be

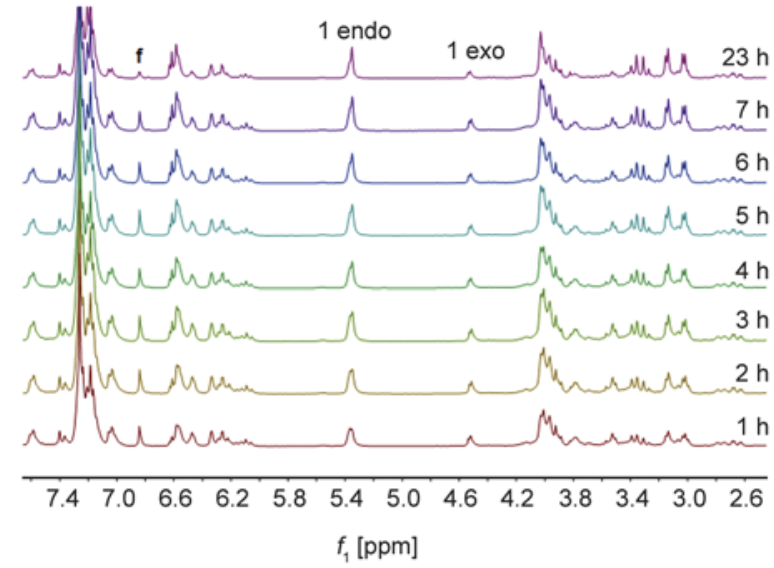

Figure 4. Superimposed ${ }^{1} \mathrm{H}-\mathrm{NMR}$ spectra of DA reaction between FA and BMI at $60^{\circ} \mathrm{C}$

formed, the ratio of exo- to endo-adducts changed with the temperature and the reaction time.

Figure 4 shows the superimposed proton NMR spectra of FA, BMI and the DA adduct formed from them at $60^{\circ} \mathrm{C}$. As seen in Figure 4 the amount of the endo to that of exo DA adduct increases with conversion. The data of Table 2 show the effects of reaction temperature and time on the formation of the DA adducts (endo + exo; unreacted). Based on the integrals of protons $\mathbf{f}$ and 1 after $23 \mathrm{~h}$ the conversion was $84 \%$, while at $100^{\circ} \mathrm{C}$ after $23 \mathrm{~h}$ the reaction almost completed. As it can be seen from these results, the DA addition reaction takes place already at room temperature with moderate conversion: i.e. the amount of the DA adducts is $54 \%$ after $23 \mathrm{~h}$ at ambient temperature. Upon raising the reaction temperature the conversion increases. Further increase in the temperature $\left(120^{\circ} \mathrm{C}\right)$ induces the rDA reaction since proton signals of the starting materials reappear in the ${ }^{1} \mathrm{H}-\mathrm{NMR}$ spectra. To support the proposed structure presented in Figure 1 , the ${ }^{1} \mathrm{H}-\mathrm{NMR}$ spectrum of PU 5 will be shown

Table 2. Composition of the reaction mixture at $25,60,80,100$ and $120^{\circ} \mathrm{C}$ based on ${ }^{1} \mathrm{H}-\mathrm{NMR}$ spectra

\begin{tabular}{|c|c|c|c|c|c|c|c|c|}
\hline \multirow{2}{*}{$\begin{array}{c}\text { Temperature } \\
{\left[{ }^{\circ} \mathrm{C}\right]}\end{array}$} & \multicolumn{8}{|c|}{ Starting material } \\
\hline & $\%(1 h)$ & $\%(2 h)$ & $\%(3 h)$ & $\%(4 h)$ & $\%(5 h)$ & $\%(6 h)$ & $\%(7 h)$ & $\%(23 h)$ \\
\hline 25 & 83 & 85 & 87 & 85 & 84 & 81 & 80 & 45 \\
\hline 60 & 31 & 30 & 28 & 27 & 28 & 26 & 21 & 16 \\
\hline 80 & 36 & 36 & 37 & 37 & 36 & 36 & 35 & 30 \\
\hline 100 & 29 & 28 & 25 & 29 & 28 & 26 & 32 & 2 \\
\hline 120 & 13 & 13 & 22 & 16 & 24 & 23 & 21 & 5 \\
\hline \multicolumn{9}{|c|}{ Product } \\
\hline & $\%(1 h)$ & $\%(2 h)$ & $\%(3 h)$ & $\%(4 h)$ & $\%(5 h)$ & $\%(6 h)$ & $\%(7 h)$ & $\%(23 h)$ \\
\hline 25 & 17 & 14 & 12 & 14 & 15 & 19 & 19 & 54 \\
\hline 60 & 68 & 69 & 71 & 73 & 71 & 74 & 78 & 84 \\
\hline 80 & 64 & 64 & 64 & 64 & 64 & 64 & 65 & 69 \\
\hline 100 & 71 & 72 & 75 & 71 & 72 & 74 & 68 & 98 \\
\hline 120 & 88 & 70 & 78 & 84 & 76 & 77 & 79 & 95 \\
\hline
\end{tabular}



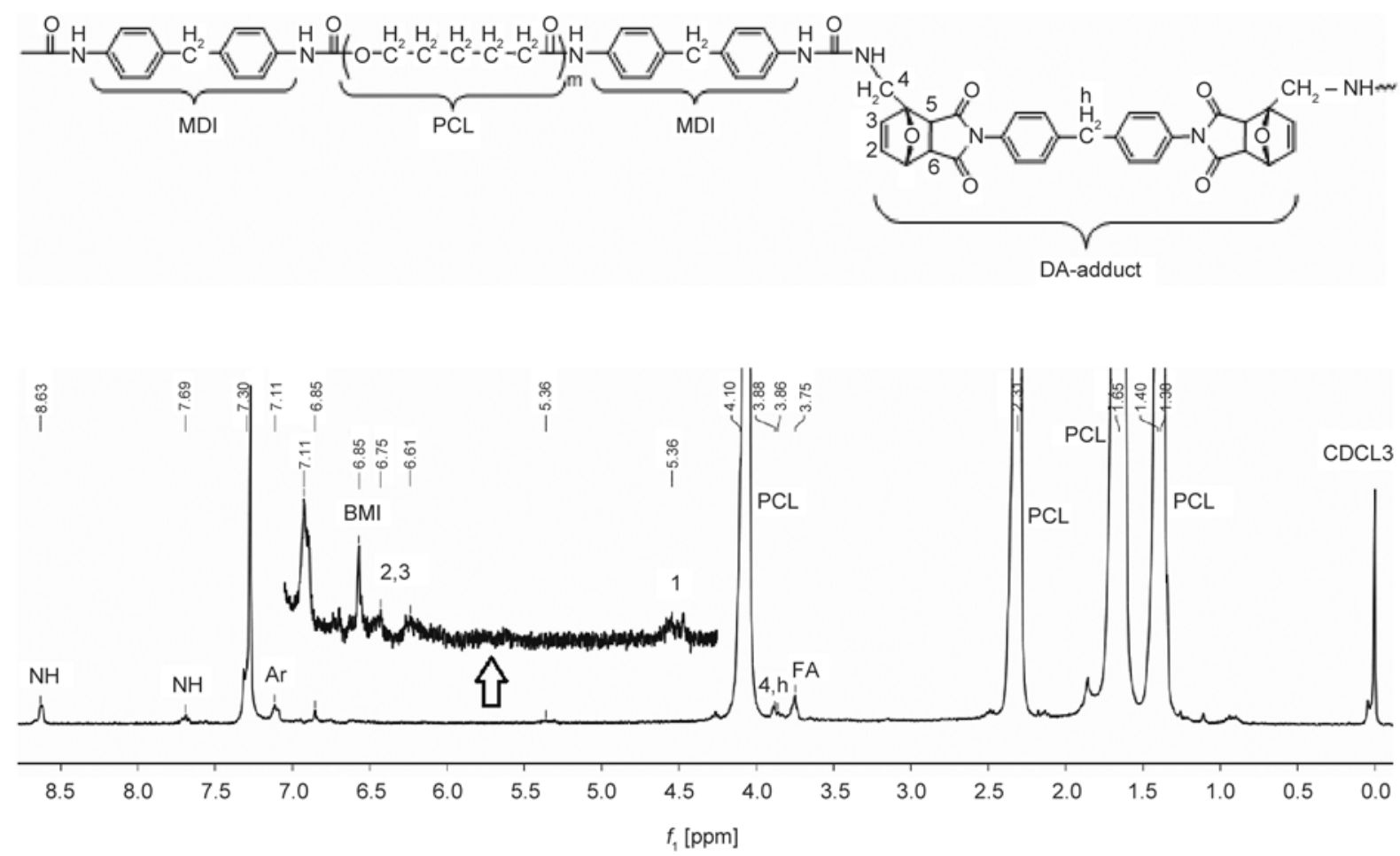

Figure 5. Structure and ${ }^{1} \mathrm{H}-\mathrm{NMR}$ spectrum of PU 5

and analyzed next. The amide, urethane or urea $\mathrm{NH}$ protons (f) of PU-5 appear in Figure 4 at 8.63, $7.69 \mathrm{ppm}$, while the aromatic signals (MDI) are visible at 7.30, $7.11 \mathrm{ppm}$. The protons (f and $\mathbf{d}$ ), which belongs to the components of DA adduct, can be found at 6.85 (BMI) and 3.75 (FA) ppm, respectively. The low intensity peaks of the adduct (1-3) are visible in the magnified insets at 6.75, 6.61 and $5.36 \mathrm{ppm}$. The $\mathrm{CH}_{2}$ proton signals of $\mathrm{PCL}$ are around 4.06, 2.31, 1.72-1.62 and $1.38 \mathrm{ppm}$ (cf. Figure 5).

The DA and rDA reactions were also studied by ${ }^{1} \mathrm{H}-\mathrm{NMR}$ spectroscopy (PU 1, Figure 6). The DA reaction was induced at $100^{\circ} \mathrm{C}$ by addition $\mathrm{FA}$ and BMI (2) to the isocyanate terminated prepolymer (1), while the cleavage of the DA adduct was followed at $125^{\circ} \mathrm{C}$ for $2 \mathrm{~h}(3)$. The peaks at $6.85,3.88 \mathrm{ppm}$ belong to FA and BMI, while those at 6.73 and $6.57 \mathrm{ppm}$ are assigned to $\mathrm{CH}$ protons of the DA adduct. In the ${ }^{1} \mathrm{H}-\mathrm{NMR}$ spectrum (3) the peaks of BMI and the DA adduct are not visible, only the low intensity peaks (6.31, 6.23 ppm) of FA appear at 3.68 ppm (Figure 6). In order to study how the heat treatment influences the properties of the PUs via completion of the DA reaction PU 2 was heated at $90^{\circ} \mathrm{C}$ for $45 \mathrm{~min}$ in a hot press. The corresponding ${ }^{1} \mathrm{H}-\mathrm{NMR}$ spectra are shown in Figure 7.

The increasing intensities of the signals related to the DA adduct at $6.72,6.55,5.36,3.13$ and $3.02 \mathrm{ppm}$,

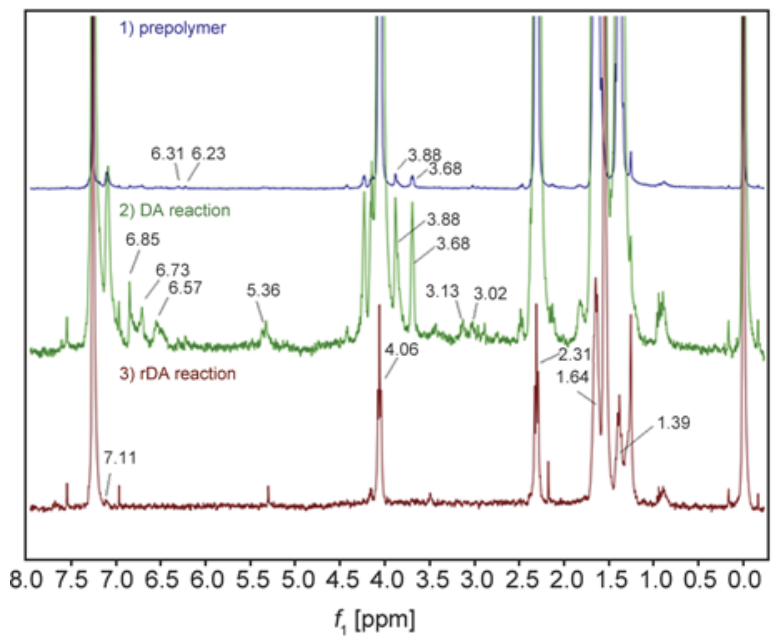

Figure 6. Investigation of the DA and $\mathrm{RDA}$ reaction by ${ }^{1} \mathrm{H}-\mathrm{NMR}$ spectroscopy in the case of PU 1

confirm that the additional thermal treatment improved DA coupling.

Further information on the chemical structure of the linear PUs was expected from AT-FTIR measurements. Figure 8 shows the IR spectra of PUs 2, 5-8. The absorption bands belonging to amide bonds -NH and amide II, are not visible in the FTIR spectra of PUs. The absorption bands at $2860,2935 \mathrm{~cm}^{-1}$, associated with $-\mathrm{CH}_{2}$ vibrations, are well identifiable. Nevertheless, no absorption band could be resolved around $2230 \mathrm{~cm}^{-1}$, indicating the complete reaction 

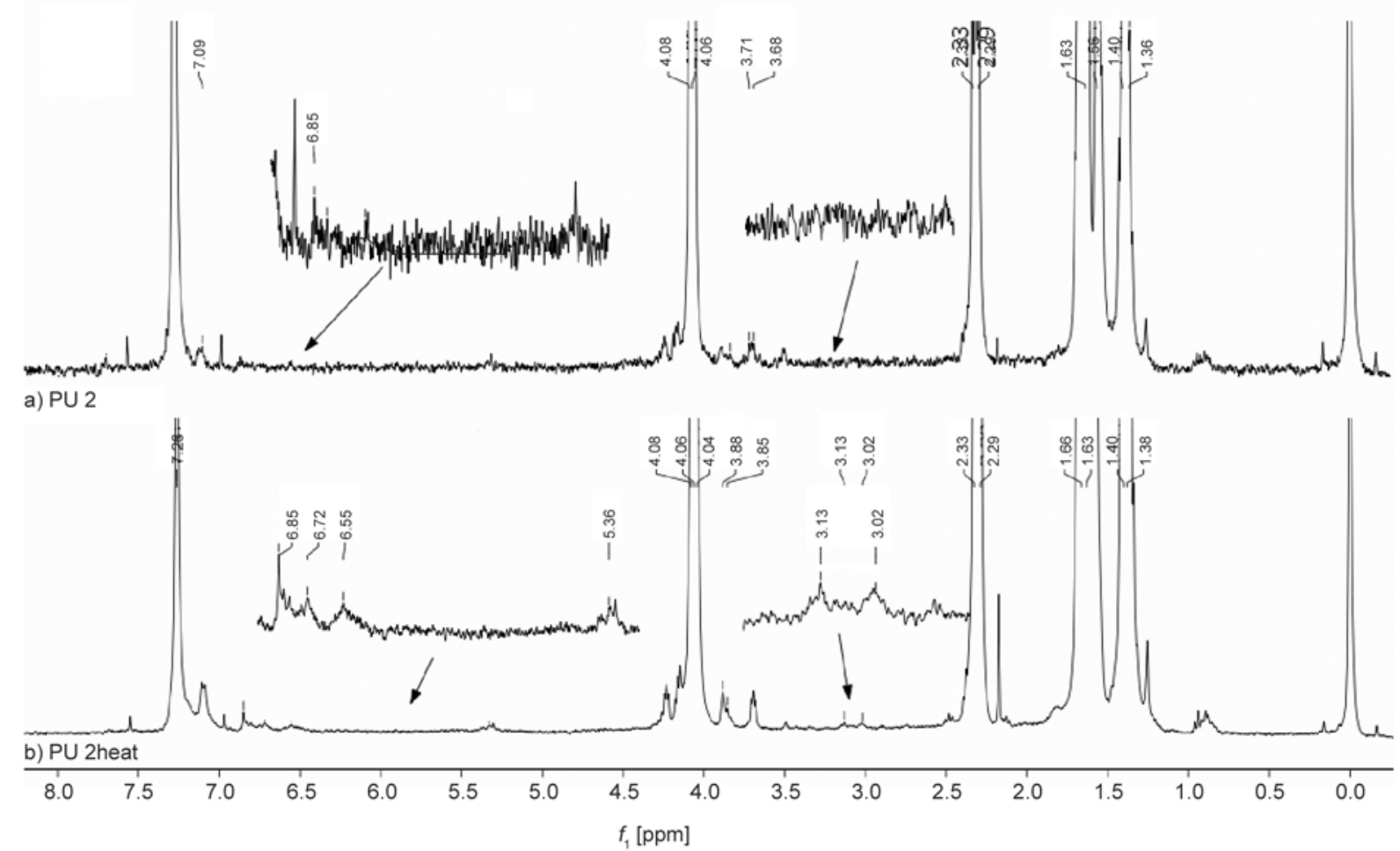

Figure 7. ${ }^{1} \mathrm{H}-\mathrm{NMR}$ spectra of PU 2 with heat treatment at $90^{\circ} \mathrm{C}$ for $45 \mathrm{~min}$ (b) and without heat treatment (a)

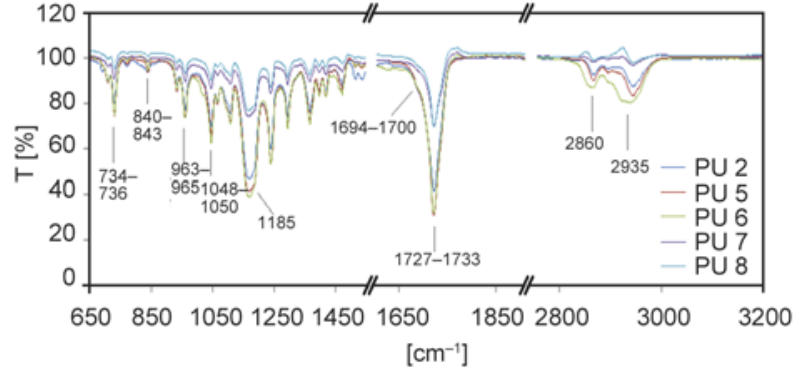

Figure 8. AT-FTIR spectra of PUs 2 and 5-8

of the NCO functional groups. The band appearing at $1185 \mathrm{~cm}^{-1}$ can be assigned to $=\mathrm{C}-\mathrm{O}$ and $-\mathrm{C}-\mathrm{O}-\mathrm{C}-$ groups (Figure 8). In the structures of segmented PUs the urethane and amide $\mathrm{NH}$ groups act as H-bond donors, while the $\mathrm{C}=\mathrm{O}$ groups in the $\mathrm{PCL}$ segments and urethane bonds overtake the role of $\mathrm{H}$-bond acceptors $[32,33]$. The H-bonded structure may influence numerous properties of the PU including e.g. the crystallization process. The presence of bond $-\mathrm{N}-\mathrm{H} \cdots \mathrm{O}=\mathrm{C}$ can be demonstrated by ATFTIR. As seen in the enlargement of $\mathrm{C}=\mathrm{O}$ band (Figure 8), the free $\mathrm{C}=\mathrm{O}$ band reflecting the ester (PCL) and urethane $\mathrm{C}=\mathrm{O}$ appears around $1727-1733 \mathrm{~cm}^{-1}$, whereas the $\mathrm{H}$-bonded $\mathrm{C}=\mathrm{O}$ is reflected by a weak shoulder between $1694-1700 \mathrm{~cm}^{-1}$. The PUs 2 and 5 were also investigated by IR spectroscopy before and after heat treatment. Our observations confirm

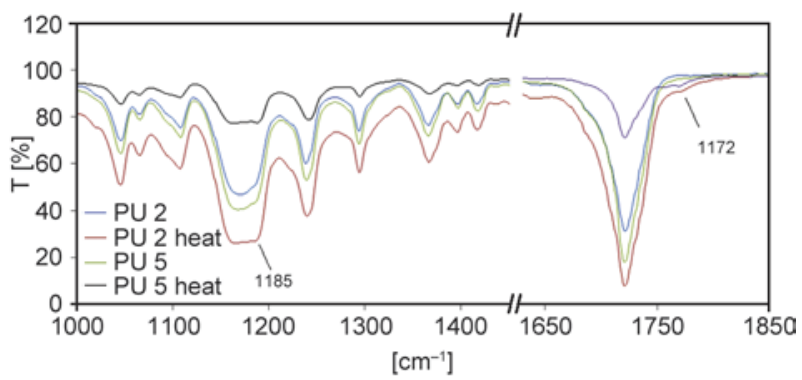

Figure 9. Comparison of the AT-FTIR spectra of PU 2 and 5 with and without thermal treatment at $90^{\circ} \mathrm{C}$ for $45 \mathrm{~min}$

also that additional DA reaction takes place upon heating, which is in good agreement with ${ }^{1} \mathrm{H}-\mathrm{NMR}$ results (see Figure 7). So, the applied heat treatment supported additional DA adduct formation.

Figure 9 reveals the FTIR spectra of PU 2 and 5 with and without additional heat treatment. In the IR spectra of heat treated PUs a band is visible at $1772 \mathrm{~cm}^{-1}(\mathrm{C}=\mathrm{O})$ and the increasing intensity of peak at $1185 \mathrm{~cm}^{-1}$ refers to an additional formation of DA-adduct [33]. The results of ${ }^{1} \mathrm{H}-\mathrm{NMR}$ and ATFTIR investigations indicate that the DA reaction in the case of high molecular weight PUs takes place at lower conversion than in the model reaction between FA and BMI. However, the DA conversion can be further enhanced by heat treatment. 


\subsection{Tensile mechanical behavior}

The mechanical properties were examined by tensile measurements and the results are summarized in Table 3. Comparing PU 1 and 2 one can recognize that increasing the BMI amount in the composition was accompanied with decreasing the stiffness $(E-$ modulus), strength (maximum and stress at break, $\sigma_{\mathrm{m}}$ and $\sigma_{\mathrm{R}}$, respectively) and ductility (elongation at maximum stress and ultimate elongation, $\varepsilon_{\mathrm{m}}$ and $\varepsilon_{\mathrm{R}}$, respectively) characteristics.

PCL ( $10 \mathrm{~kg} / \mathrm{mol})$ combined with MDI showed good mechanical properties (PUs 1 and 2), the tensile strength $\left(\sigma_{\mathrm{R}}\right) 18$ and $19 \mathrm{MPa}$. Applying HDI and TDI instead of MDI (PU 3, 4), PUs with poorer mechanical properties were obtained, which can be attributed to the decreasing molecular weight of the corresponding PUs (see Table 1.) In the series of PUs 5-10 containing PCL of $M_{\mathrm{n}}=25$ and $50 \mathrm{~kg} / \mathrm{mol}$ (PUs 6 and 9) PCLs resulted in polymers with the highest tensile strength $\left(\sigma_{\mathrm{R}}\right) 22$ and $25 \mathrm{MPa}$ and elongation $\left(\varepsilon_{\mathrm{R}}\right) 619$ and $580 \%$. This may be due to the higher flexibility provided by HDI. However, it should be noted that the $E$-modulus increased, which may be linked with a higher secondary bond (H-bonds, Van der Waals interactions) density. Considering the HDI containing PU series, i.e., PUs 3, 6 and 9, one can observe that the stiffness, strength and ductility data steeply increase with increasing molecular weight of the PCL from $M_{\mathrm{n}}=10 \mathrm{~kg} / \mathrm{mol}$ to $25 \mathrm{~kg} / \mathrm{mol}$. However, incorporation of PCL with $M_{\mathrm{n}}=50 \mathrm{~kg} / \mathrm{mol}$ resulted in a small drop in each of the above mechanical parameters. In contrast, for the TDI series a different scenario can be observed. Unlike PUs 4 and 10 having the lowest and highest $M_{\mathrm{n}}$ of PCL incorporated into the chain, poor mechanical data were

Table 3. Tensile mechanical properties of the PUs (PUs 110). Designations: E-elastic modulus (Young's modulus), $\sigma_{\mathrm{m}}-$ maximum stress, $\varepsilon_{\mathrm{m}}-$ elongation at the maximum stress, $\varepsilon_{\mathrm{R}}-$ is the ultimate elongation, and $\sigma_{\mathrm{R}}-$ is the stress at break

\begin{tabular}{|l|l|c|r|r|r|}
\hline Code & $\begin{array}{c}\boldsymbol{E} \\
{[\mathbf{M P a}]}\end{array}$ & $\begin{array}{c}\boldsymbol{\varepsilon}_{\mathbf{m}} \\
{[\boldsymbol{\%}]}\end{array}$ & $\begin{array}{c}\boldsymbol{\sigma}_{\mathbf{m}} \\
{[\mathbf{M P a}]}\end{array}$ & $\begin{array}{c}\boldsymbol{\varepsilon}_{\mathbf{R}} \\
{[\boldsymbol{\%}]}\end{array}$ & $\begin{array}{c}\boldsymbol{\sigma}_{\mathbf{R}} \\
{[\mathbf{M P a}]}\end{array}$ \\
\hline PU 1 & $360 \pm 9$ & $490 \pm 4$ & $18 \pm 0.6$ & $490 \pm 4$ & $18 \pm 0.6$ \\
\hline PU 2 & $179 \pm 22$ & $778 \pm 9$ & $19 \pm 0.7$ & $778 \pm 9$ & $19 \pm 0.7$ \\
\hline PU 3 & $113 \pm 15$ & $165 \pm 76$ & $9 \pm 0.5$ & $165 \pm 76$ & $9 \pm 0.5$ \\
\hline PU 4 & $162 \pm 11$ & $175 \pm 55$ & $9 \pm 1.0$ & $175 \pm 55$ & $9 \pm 1.0$ \\
\hline PU 5 & $179 \pm 36$ & $695 \pm 107$ & $15 \pm 4.0$ & $695 \pm 107$ & $15 \pm 4.0$ \\
\hline PU 6 & $383 \pm 21$ & $619 \pm 23$ & $25 \pm 0.4$ & $619 \pm 23$ & $25 \pm 0.4$ \\
\hline PU 7 & $145 \pm 66$ & $16 \pm 5$ & $6 \pm 2.0$ & $26 \pm 8$ & $5 \pm 0.6$ \\
\hline PU 8 & $174 \pm 34$ & $75 \pm 45$ & $9 \pm 0.7$ & $160 \pm 45$ & $10 \pm 2.0$ \\
\hline PU 9 & $285 \pm 26$ & $580 \pm 63$ & $22 \pm 0.1$ & $580 \pm 63$ & $22 \pm 0.1$ \\
\hline PU 10 & $235 \pm 41$ & $102 \pm 30$ & $13 \pm 1.0$ & $102 \pm 30$ & $13 \pm 1.0$ \\
\hline
\end{tabular}

found for PU 7 containing PCL with $M_{\mathrm{n}}=25 \mathrm{~kg} / \mathrm{mol}$. The best mechanical performance can be attributed to the MDI series of the PUs (PU 2, 5 and 8), especially when they contained PCLs with $M_{\mathrm{n}}=10$ and $25 \mathrm{~kg} / \mathrm{mol}$ as soft segments (PU 2 and 5). Therefore, these polymers were studied with respect to shapememory properties.

\subsection{Thermal, thermo-mechanical and shape memory behavior}

DA adduct formation provides a reversible linkage between the PCL-based prepolymers thereby enhancing the molecular weight of the resulting PU. Longer chains participate in more molecular entanglements and affect the final morphology (physical crosslink structure), which may be associated with better SM performance. Furthermore, DA adducts may overtake the role of reversible 'switch' in SMPUs, as well. However, as underlined before, the reversible main 'switch' function of this series of SMPUs is due to the melting and crystallization of the PCL segments. On the other hand, the DA bonding between the furan and maleimide may influence the crystallization of PCL and thus affect the shape memory properties. For this reasons, the crystallization behavior of PCL in selected PUs (PUs 1-3, 5, 6, 8 and 9) was investigated by DSC (see Figure 10). The data obtained from the DSC curves and the calculated crystallinity values are summarized in Table 4 .

As shown in Figure 10 only the melting peaks of PCL were detected by DSC measurements. No thermal effects belonging to the DA adducts appeared in the DSC curves. The latter, might be hidden by the PCL melting. Furthermore, the crystallinity of polyurethanes can be influenced by the length of the soft segment and the amount of hard segment [34]. Considering PUs 1 and 2 the higher BMI amount seems

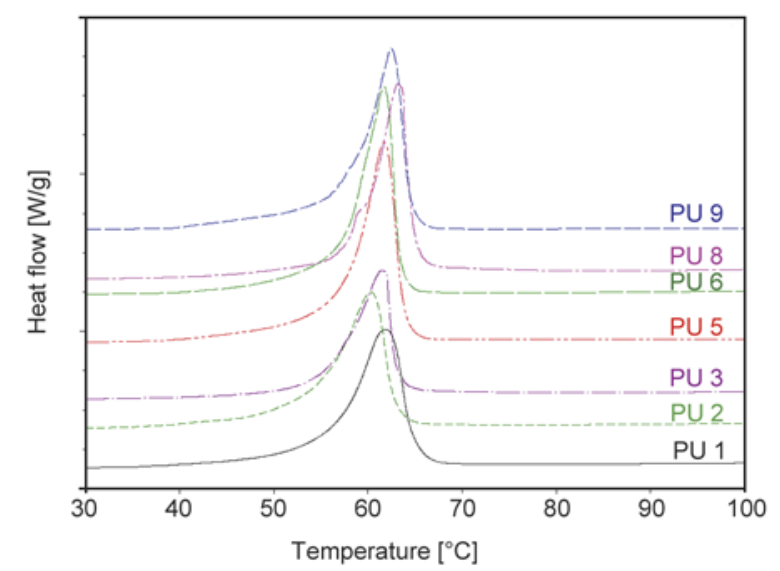

Figure 10. DSC curves of PUs $1-3,5,6,8$ and 9 
Table 4. Melting temperature $\left(T_{\mathrm{m}}\right)$, melting enthalpy $\left(\Delta H_{\mathrm{m}}\right)$ and crystallinity values obtained from DSC measurements

\begin{tabular}{|c|c|c|c|c|c|}
\hline Code & $\begin{array}{c}\mathbf{P C L} \boldsymbol{M}_{\mathbf{n}} \\
{[\mathbf{k g} / \mathbf{m o l}]}\end{array}$ & $\begin{array}{c}\boldsymbol{T}_{\mathbf{m}} \\
{\left[{ }^{\circ} \mathbf{C}\right]}\end{array}$ & $\begin{array}{c}\text { PCL } \\
{[\mathbf{w t} \%]}\end{array}$ & $\begin{array}{c}\Delta \boldsymbol{H}_{\mathbf{m}} \\
{[\mathbf{J} / \mathbf{g}]}\end{array}$ & $\begin{array}{c}\text { Crystallinity } \\
{[\%]}\end{array}$ \\
\hline PU 1 & 10 & 61.8 & 88.5 & 74.6 & 62.0 \\
\hline PU 2 & 10 & 60.3 & 86.0 & 65.6 & 56.5 \\
\hline PU 3 & 10 & 61.4 & 90.0 & 49.9 & 41.0 \\
\hline PU 5 & 25 & 61.6 & 94.0 & 85.8 & 68.0 \\
\hline PU 6 & 25 & 61.8 & 95.0 & 78.7 & 61.5 \\
\hline PU 8 & 50 & 63.1 & 97.0 & 66.7 & 51.0 \\
\hline PU 9 & 50 & 62.5 & 97.0 & 81.2 & 62.0 \\
\hline
\end{tabular}

to reduce the crystallinity thereby lowering $T_{\mathrm{m}}$, as well. With the increasing $M_{\mathrm{n}}$ of PCL, the PCL crystallinity shows maximum for the MDI series (cf. PU 2, 5 , and 8 in Table 4). Based on these results PU 5 has the highest crystallinity, which may explain the better shape memory properties. No change in the crystallinity was detected, when the $M_{\mathrm{n}}$ of PCL was increased for the HDI containing PUs (cf. PU 6 and

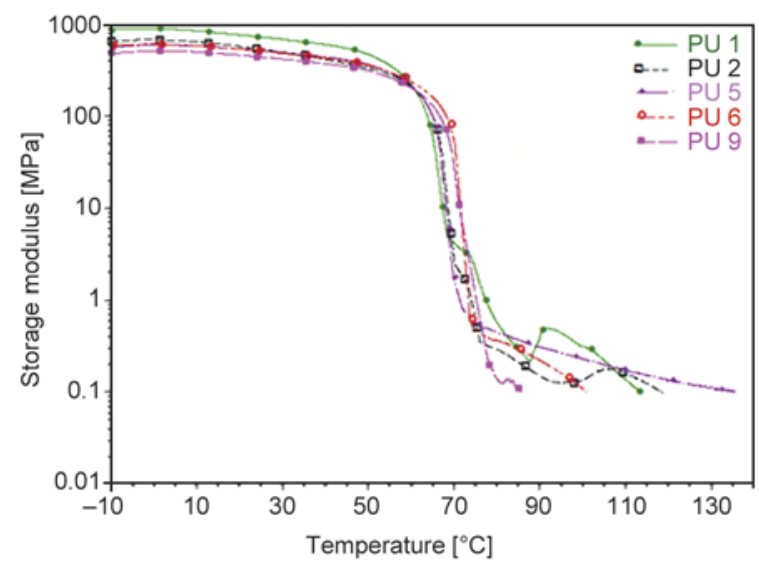

Figure 11. Storage modulus as a function of temperature for PUs $1,2,5,6$ and 9

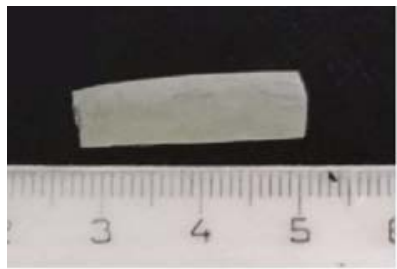

a)

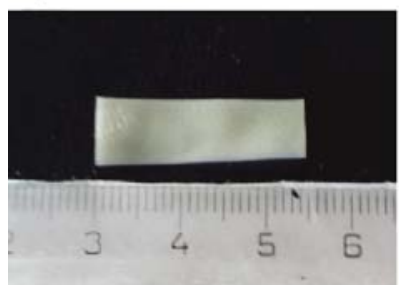

d)

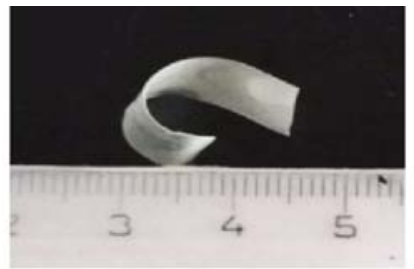

b)

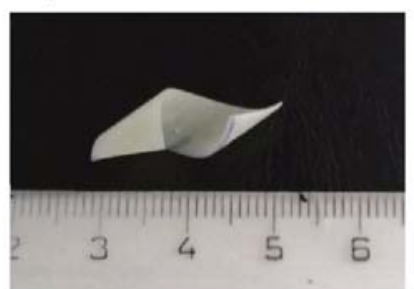

e)
9 in Table 4). However, the crystallinity of the PU decreased, when the main segment was PCL with $M_{\mathrm{n}}=10 \mathrm{kDa}(\mathrm{PU} 3)$. The reason for this may be linked with the flexibility of HDI.

Thermal stability and shape memory properties of PUs were analyzed by dynamic mechanical analysis (DMA) using tensile mode. Storage modulus of PUs 1, 2, 5, 6 and 9 as a function of temperature are shown in Figure 11. The DMA curves exhibit rubbery-like plateau above $T_{\mathrm{m}}$ of the PCL for PU 1, 2, 5 and 6 . No such feature could be detected for PU 9. The term rubbery-like is used due to some analogy with the rubbery plateau in crosslinked polymers. The fact that it is declining with increasing temperature is a confirmation for the presence of a segregated morphology in the physically networked thermoplastic PUs. Nevertheless, the presence of this plateau is an excellent tool for SM programming [35]. In the DMA traces of PUs 1 and 2, containing PCL of $M_{\mathrm{n}}=$ $10 \mathrm{~kg} / \mathrm{mol}$, additional peaks can be found in this rubber-like plateau region. These additional peaks may be due to the microstructure of the PUs and/or to the advancement of the DA coupling which was also confirmed by ${ }^{1} \mathrm{H}-\mathrm{NMR}$ and AT-FTIR spectroscopy. PUs 2 and 5 showing well developed rubbery-like plateaus were subjected to SM tests. First thin strips cut of PU 2 and 5 were tested for shape memory performance (Figure 12). The samples were deformed at $70^{\circ} \mathrm{C}$ (i.e. above the melting temperature of PCL block) in water bath and then cooled to room temperature to set the temporary shape. Its re-immersion in the warm water bath resulted in the expected shape recovery.

Figure 12. Illustration of the shape memory behavior for PU $2(a-c)$ and PU $5(d-f)$ : a, d) permanent, b, e) temporary, $\mathrm{c}, \mathrm{f})$ recovered shape 
The SM behavior was quantified in tensile loading using the DMA device. PUs 2 and 5 had similar shape fixities $\left(R_{\mathrm{f}}=99\right.$ and $100 \%$, respectively) after deformation at $80^{\circ} \mathrm{C}$ for $80 \%$ strain. The shape recovery of PU 5 at $80^{\circ} \mathrm{C}\left(R_{\mathrm{r}}=56 \%\right)$ was higher than the PU 2 version containing PCL with $M_{\mathrm{n}}=10 \mathrm{~kg} / \mathrm{mol}$ $\left(R_{\mathrm{r}}=43 \%\right)$. The reason for this is most likely linked with the difference in the main segments' molecular weights, viz. PCLs with 25 and $10 \mathrm{~kg} / \mathrm{mol}$. Thus PU 2 has lower crystallinity and reduced elasticity which affect negatively the shape recovery. It is supposed, however, that $R_{\mathrm{r}}$ changes as a function of the shape programming, i.e. temperature and strain values. It is noteworthy that due to rubber-like behavior and the thermoreversible feature of the DA coupling, these PUs may show shape memory assisted self healing $[36,37]$ that will be checked next.

\section{Conclusions}

DA reaction was applied for the preparation of thermoreversible bond containing linear segmented polyurethanes (PUs). The soft segments composed of poly( $\varepsilon$-caprolactone) (PCL) with different molecular weights $\left(M_{\mathrm{n}}=10,25\right.$ and $\left.50 \mathrm{~kg} / \mathrm{mol}\right)$, while the hard segments were three types of diisocyanates (4,4'-methylene diphenyl diisocyanate (MDI), 2,4toluene diisocyanate (TDI), 1,6-hexamethylene diisocyanate (HDI)), furfurylamine (FA) and 1,1'-(methylene di-4,1-phenylene)bismaleimide (BMI). The molecular weight of the linear PUs was determined by size-exclusion chromatography (SEC) and varied from 53.6 to $116.7 \mathrm{~kg} / \mathrm{mol}$. It was demonstrated that heat treatment close to the melting temperature $\left(T_{\mathrm{m}}\right)$ of PCL supported the DA reaction. The PCLrelated crystallinity of the PUs changed slightly as a function of PCL molecular weight and diisocyanate type. This was attributed to the effects of H-bonding and characteristics of the hard segments formed. MDI and HDI outperformed the TDI-containing PUs with respect to the mechanical performance irrespective of the PCL molecular weight. The stiff molecular structure of MDI proved to be beneficial for the mechanical performance of PUs with PCL of $10 \mathrm{~kg} / \mathrm{mol}$ molecular weight, while the more flexible HDI worked well in the PUs with higher molecular weight PCL ( $50 \mathrm{~kg} / \mathrm{mol})$. Above $T_{\mathrm{m}}$ of the PCL a well-developed rubber-like plateau was found attesting the efficient physical networking via the hard segments composed of isocyanates and DA adducts. This plateau range allows to set different programming for shape memory function that was shown on selected examples. The good recovery along with the thermoreversible feature of the DA adducts are prerequisites of shape memory assisted self-healing which, however, still has to be confirmed.

\section{Acknowledgements}

The work reported here was supported by the TÁMOP4.2.2.A-11/1/KONV-2012-0036 project, co-financed by the European Union and the European Social Fund, and by a grant of the Hungarian Research Funds (OTKA SNN 114547). This work was also supported by the European Union and the State of Hungary, co-financed by the European Social Fund in the framework of TÁMOP-4.2.4.A/ 2-11/1-20120001 'National Excellence Program' (S. K.).

\section{References}

[1] Sonnenschein M. F.: Polyurethanes-science, technology, markets, and trends. Whiley, New York (2015).

[2] Smirnova N. N., Kandeev K. V., Markin A. V., Bykova T. A., Kulagina T. G., Fainleib A. M.: Thermodynamics of linear polyurethanes on basis of 1,4-diisocyanatobutane with 1,4-butanediol and 1,6-hexanediol in the range from $T \rightarrow 0$ to $490 \mathrm{~K}$. Thermochimica Acta, 445, 7-18 (2006).

DOI: $10.1016 /$ j.tca.2006.03.017

[3] Chattopadhyay D. K., Raju K. V. S. N.: Structural engineering of polyurethane coatings for high performance applications. Progress in Polymer Science, 32, 352-418 (2007).

DOI: $10.1016 /$ j.progpolymsci.2006.05.003

[4] Shmidt R. S.: NASA pressure-relieving foam technology is keeping the leading innerspring mattress firms awake at night. Technovation, 29, 181-191 (2009). DOI: $10.1016 /$ j.technovation.2008.06.004

[5] Ippili R. K., Davies P., Bajaj A. K., Hagenmeyer L.: Nonlinear multi-body dynamic modeling of seat-occupant system with polyurethane seat and H-point prediction. International Journal of Industrial Ergonomics, 38, 368-383 (2008).

DOI: 10.1016/j.ergon.2007.08.014

[6] Korodi T., Marcu N.: Polyurethane microcellular elastomers: 1. Effect of chemical composition on tensile strength and elongation at break of poly(ethylene-butylene adipate) based systems. Polymer, 24, 1321-1326 (1983).

DOI: 10.1016/0032-3861(83)90067-8

[7] Ashton J. H., Mertz J. A. M., Harper J. L., Slepian M. J., Mills J. L., McGrath D. V., Van de Geest J. P.: Polymeric endoaortic paving: Mechanical, thermoforming, and degradation properties of polycaprolactone/polyurethane blends for cardiovascular applications. Acta Biomaterialia, 7, 287-294 (2011).

DOI: $10.1016 /$ j.actbio.2010.09.004 
[8] Arena G., Friedrich K., Acierno D., Padenko E., Russo P., Filippone G., Wagner J.: Solid particle erosion and viscoelastic properties of thermoplastic polyurethanes. Express Polymer Letters, 9, 166-176 (2015). DOI: $10.3144 /$ expresspolymlett.2015.18

[9] Tian Q., Almásy L., Yan G., Sun G., Zhou X., Liu J., Krakovsky I., Veres M., Rosta L., Chen B.: Small-angle neutron scattering investigation of polyurethane aged in dry and wet air. Express Polymer Letters, 8, 345-351 (2014). DOI: 10.3144/expresspolymlett.2014.38

[10] Karger-Kocsis J., Kéki S.: Biodegradable polyesterbased shape memory polymers: concepts of (supra)molecular architecturing. Express Polymer Letters, 8, 397412 (2014).

DOI: $10.3144 /$ expresspolymlett.2014.44

[11] Xiao R., Nguyen T. D.: Thermo-mechanics of amorphous shape-memory polymers. Procedia IUTAM, 12, 154-161 (2015).

DOI: $10.1016 /$ j.piutam.2014.12.017

[12] Tobushi H., Okumura K., Hayashi S., Ito N.: Thermomechanical constitutive model of shape memory polymer. Mechanics of Materials, 33, 545-554 (2001).

DOI: 10.1016/S0167-6636(01)00075-8

[13] Hu J., Zhu Y., Huang H., Lu J.: Recent advances in shape-memory polymers: Structure, mechanism, functionality, modeling and applications. Progress in Polymer Science, 37, 1720-1763 (2012).

DOI: $10.1016 /$ j.progpolymsci.2012.06.001

[14] Ratna D., Karger-Kocsis J.: Recent advances in shape memory polymers and composites: A review. Journal of Materials Science, 43, 254-269 (2008).

DOI: $10.1007 / \mathrm{s} 10853-007-2176-7$

[15] Meng H., Li G.: A review of stimuli-responsive shape memory polymer composites. Polymer, 54, 2199-2221 (2013).

DOI: $10.1016 /$ j.polymer.2013.02.023

[16] Berg G. J., McBride M. K., Wang C., Bowman C. N.: New directions in the chemistry of shape memory polymers. Polymer, 55, 5849-5872 (2014). DOI: $10.1016 /$ j.polymer.2014.07.052

[17] Ramoa S. D. A. S., Barra G. M. O., Merlini C., Livi S., Soares B. G., Pegoretti A.: Novel electrically conductive polyurethane/montmorillonite-polypyrrole nanocomposites. Express Polymer Letters, 9, 945-958 (2015). DOI: $10.3144 /$ expresspolymlett.2015.85

[18] Karger-Kocsis J., Kéki S.: Recent advances in shape memory epoxy resins and composites. in 'Multifunctionality of polymer composites' (eds.: Friedrich K., Breuer U.) William Andrew, Oxford, 822-841 (2015) DOI: $10.1016 / \mathrm{B} 978-0-323-26434-1.00027-1$

[19] Hager M. D., Bode S., Weber C., Schubert U. S.: Shape memory polymers: Past, present and future developments. Progress in Polymer Science, 49-50, 3-33 (2015). DOI: $10.1016 /$ j.progpolymsci.2015.04.002
[20] Hillewaere X. K. D., Du Prez F. E.: Fifteen chemistries for autonomous external self-healing polymers and composites. Progress in Polymer Science, 49-50, 121-153 (2015).

DOI: $10.1016 /$ j.progpolymsci.2015.04.004

[21] Liu Y-L., Hsieh C-Y., Chen Y-W.: Thermally reversible cross-linked polyamides and thermo-responsive gels by means of Diels-Alder reaction. Polymer, 47, 25812586 (2006).

DOI: $10.1016 /$ j.polymer.2006.02.057

[22] Araya-Hermosilla R., Broekhuis A. A., Picchioni F.: Reversible polymer networks containing covalent and hydrogen bonding interactions. European Polymer Journal, 50, 127-134 (2014).

DOI: $10.1016 / j$.eurpolymj.2013.10.014

[23] Laita H., Boufi S., Gandini A.: The application of the Diels-Alder reaction to polymers bearing furan moieties. 1. Reactions with maleimides. European Polymer Journal, 33, 1203-1211 (1997).

DOI: 10.1016/S0014-3057(97)00009-8

[24] Henschel H., Kirsch N., Hedin-Dahlström J., Whitcombe M. J., Wikman S., Nicholls I. A.: Effect of the cross-linker on the general performance and temperature dependent behaviour of a molecularly imprinted polymer catalyst of a Diels-Alder reaction. Journal of Molecular Catalysis B: Enzymatic, 72, 199-205 (2011). DOI: $10.1016 /$ j.molcatb.2011.06.006

[25] Heo Y., Sodano H. A.: Self-healing polyurethanes with shape recovery. Advanced Functional Materials, 24, 5261-5268 (2014).

DOI: $10.1002 / \mathrm{adfm} .201400299$

[26] Bose R. K., Kötteritzsch J., Garcia S. J., Hager M. D., Schubert U. S., van der Zwaag S.: A rheological and spectroscopic study on the kinetics of self-healing in a single-component Diels-Alder copolymer and its underlying chemical reaction. Journal of Polymer Science Part A: Polymer Chemistry, 52, 1669-1675 (2014).

DOI: $10.1002 /$ pola.27164

[27] Chen X., Dam M. A., Ono K., Mal A., Schen H., Nutt S. R., Sheran K., Wudl F.: A thermally re-mendable cross-linked polymeric material. Science, 295, 16981702 (2002).

DOI: $10.1126 /$ science. 1065879

[28] Czifrák K., Karger-Kocsis J., Daróczi L., Zsuga M., Kéki S.: Poly(E-caprolactone) and pluronic diol-containing segmented polyurethanes for shape memory performance. Macromolecular Chemistry and Physics, 215, 1897-1907 (2014).

DOI: $10.1002 / \mathrm{macp} .201400237$

[29] Lendlein A., Schmidt M. A., Langer R.: AB-polymer networks based on oligo( $\varepsilon$-caprolactone) segments showing shape-memory properties. Proceeding of the National Academy of Sciences of the United States of America, 98, 842-847 (2001). DOI: $10.1073 /$ pnas.031571398 
[30] Jiang S., Ji X., An L., Jiang B.: Crystallization behavior of PCL in hybrid confined environment. Polymer, 42, 3901-3907 (2001).

DOI: $10.1016 / \mathrm{S} 0032-3861(00) 00565-6$

[31] Crescenzi V., Manzini G., Calzolari G., Borri C.: Thermodynamics of fusion of poly- $\beta$-propiolactone and poly- $\varepsilon$-caprolactone. comparative analysis of the melting of aliphatic polylactone and polyester chains. European Polymer Journal, 8, 449-463 (1972). DOI: 10.1016/0014-3057(72)90109-7

[32] Ren Z-Y., Wu H-P., Ma J-M., Ma D-Z.: FTIR studies on the model polyurethane hard segments based on a new waterborne chain extender dimethylol butanoic acid (DMBA). Chinese Journal of Polymer Science, 22, 225-230 (2004).

[33] Adachi K., Achimuthu A. K., Chujo Y.: Synthesis of organic-inorganic polymer hybrids controlled by DielsAlder reaction. Macromolecules, 37, 9793-9797 (2004). DOI: $10.1021 / \mathrm{ma} 0400618$
[34] Li F., Hou J., Zhu W., Zhang X., Xu M., Luo X., Ma D., Kim B. K.: Crystallinity and morphology of segmented polyurethanes with different soft-segment length. Journal of Applied Polymer Science, 62, 631638 (1996).

DOI: $10.1002 /(\mathrm{SICI}) 1097-4628(19961024) 62: 4<631:$ : AID-APP6>3.0.CO;2-U

[35] Yakacki C. M., Nguyen T. D., Likos R., Lamell R., Guigou D., Gall K.: Impact of shape-memory programming on mechanically-driven recovery in polymers. Polymer, 52, 4947-4954 (2011).

DOI: 10.1016/j.polymer.2011.08.027

[36] Rodriguez E. D., Luo X., Mather P. T.: Linear/network poly( $\varepsilon$-caprolactone) blends exhibiting shape memory assisted self-healing (SMASH). Applied Materials and Interfaces, 3, 152-161 (2011).

DOI: $10.1021 / \mathrm{am} 101012 \mathrm{c}$

[37] Karger-Kocsis J., Mahmood H., Pegoretti A.: Recent advances in fiber/matrix interphase engineering for polymer composites. Progress in Materials Science, 73, 143 (2015).

DOI: $10.1016 /$ j.pmatsci.2015.02.003 